\title{
EXTENDING IFC TO SUPPORT THERMAL COMFORT PREDICTION DURING DESIGN
}

\author{
Fawaz Alshehri $^{1}$, Paul Kenny ${ }^{2}$, Cathal Hoare ${ }^{1}$, Mohammad Shamsi ${ }^{1}$, \\ Usman Ali ${ }^{1}$ and James O'Donnell ${ }^{1}$ \\ ${ }^{1}$ School of Mechanical and Materials Engineering and UCD Energy Institute, \\ University College Dublin, Ireland \\ ${ }^{2}$ School of Architecture, Planning and Environmental Policy, \\ University College Dublin, Ireland
}

\begin{abstract}
During the early design stage, designers often rely on general rules of thumb to make critical decisions about the geometry, construction systems and materials without fully evaluating their effects on indoor thermal environment requirements and constraints. Currently, reviewing a design's sustainability requires designers to spend a significant amount of time manually extracting Thermal Comfort (TC) data from BIMs because of the tedious nature of this task. This paper is motivated by the absence of a standard method and a schema for extracting the necessary data for an automated TC assessment of building designs. The aim is to generate a reusable and retrievable set of Exchange Requirement's for BIM-based BTCS to facilitate efficient data extraction and exchanges from design models using the IFC file format. Furthermore, we develop an MVD mechanism that provides a structured framework for the definition and exchange of the target data as a step towards standardisation and production of BTCS related information, the results from which contribute to a proposed MVD. The application of the MVD in building design has the potential to improve the early-stage TC assessment of design alternatives. Further, it could reduce the time required to conduct the assessment, increase the reproducibility of results, and formalises the method used.
\end{abstract}

\section{Introduction}

The EU has set out ambitious strategies to improve the built environment and develop new low-energy buildings in order to reduce greenhouse gas emissions and meet targets by 2020 (European Parliament 2010). It is widely known that the most significant design decisions regarding building sustainability are generally made in the preliminary design phases of a project by stakeholders' (Bragança et al. 2014).

Building simulation is one of the most widely used design tools employed to predict thermal performance and indoor environmental conditions during a building's lifecycle (Soares et al. 2017). At present, Building Thermal Comfort Simulation (BTCS) is often evaluated in parallel with the energy performance assessment of buildings (Szelag 2017), i.e. by using the same Energy model. Many input parameters in these models are based on standard energy efficiency requirements and energy assumptions (Sanhudo et al. 2018), thus the thermal comfort simulation is assessed based on the input data for Building Energy Performance Simulation models (BEPS) models. As a result, the input parameters used by BEPS models do not fully represent thermal comfort performance criteria and do not consider the needs of the end-user or occupant.

In current practice, modellers use traditionally generated CAD drawings and create independent simulation models that are uncorrelated with the original architectural model (Jung et al. 2018). Separate models may be created to ensure that all needed information is correctly included and is suitable for design and simulation of thermal comfort. BIM-based methods now contribute to effective design progression and information availability and can help to increase the efficiency of building use by facilitating data input for simulation and allowing more scenarios to be investigated (Kim et al. 2015).

It is clear from a search of the literature that only weak interoperability (low-fidelity data exchange) exists between BIM and BTCS and this has hindered the development of fully verified, indoor thermal conditions prediction based design. The reasons for this problem include:

1. Massive BIM data presents problems around adoption for sustainability analysis (Kim \& Yu 2016);

2. Poor data exchange between BIM tools and performance assessment tools (Tuohy \& Murphy 2015) in the context of performance-based design development;

3. Well defined industry standards for green BIM do not exist (Holmström et al. 2015);

4. Low industrial acceptance of green BIM applications, even though many BIM studies have been conducted (Kassem et al. 2014) and; 
5. At present, there is a general lack of interoperability between BIM platforms and BTCS, which is also problematic and limits the use of BIM-based prediction models in indoor environmental analysis (Jung et al. 2018).

This paper aims to define the essential Exchange Requirements (ERs) parameters for BIM-based BTCS assessment at the early design stage of a commercial building design. No set of data currently exists to provide the required information instances to support BIM-based BTCS assessment of building designs within the Architects, Engineers, Contractors, Owners and Operators (AECOO) Industries. Designers still may not know essential Thermal Comfort parameters affecting occupants' thermal sensation or they do not know how to capture these parameters to perform the analysis. The goal of this research question is to specify the information designers need for the BTCS assessment during building designs and to provide a basis for the content of the ERs model. This research established the following objectives;

1. Identify and arrange the essential Thermal Comfort parameters of building designs;

2. Formulate ERs model for BTCS assessment of building designs through identify entities and their components within the set of attributes, which define the base of MVD concepts will be used in the exchange.

This paper is structured as follows: Section 2 reviews the current models for predicting thermal comfort and identifies the most common thermal comfort models and their parameters. Section 3 presents a review of the current literature on BIM for sustainable design and BIM data files exchange format, in addition, highlighted the existing related MVDs. Section 4 presents the methodology and the workflow that involved for transforming BIM to BTCS, followed by discusses the full stages of IFC MVD mapping process. Section 5 is a discussion, followed by conclusions in the last section.

\section{Predicting Thermal Comfort}

Thermal comfort is largely a state of mind, separate from equations for heat and mass transfer and energy balances. The most common approach for describing thermal comfort for the purposes of prediction and building was introduced by P.O. Fanger in 1970. The model looks at five input variables: operative temperature $\left({ }^{\circ} \mathrm{C}\right)$, air speed $(\mathrm{m} / \mathrm{s})$, relative humidity (\%), metabolic rate (Met) and clothing insulation level (Clo).

In recent years, levels of comfort are often characterised using the ASHRAE thermal sensation scale shown in Figure 1 . The average thermal sensation response of a large number of subjects, using the ASHRAE 55 thermal sensation scale, is called the Predicted Mean Vote (PMV) or the Predicted Percentage Dissatisfied (PPD) (ASHARE 2013). EN ISO 7730 presents the PMV and PPD indices based on the well-known theory of Fanger (EN-ISO-7730 2005).

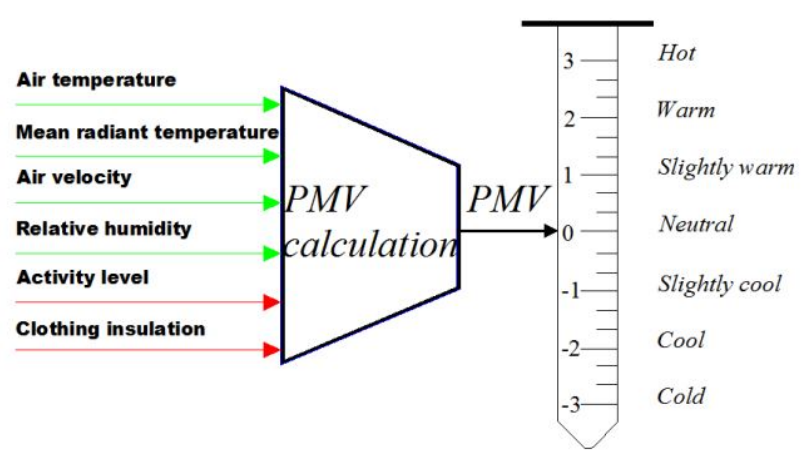

Figure 1: Calculation variables and value scale of PMV (ASHARE 2013).

Current standards such as ASHRAE 55 standard and EN ISO 7730 standard specify methods for the evaluation of the thermal environment of buildings in order to obtain a certain degree of global comfort for the occupants at a certain level of activity and clothing (Yau \& Chew 2014). These standards have been implemented in most BEPS tools that are available for predicting peoples' thermal comfort in buildings.

Another innovative comfort model was developed by (de Dear \& Brager 1998) and commonly known as an adaptive model of thermal comfort. The model accounts for comfort by relating the acceptable range of indoor temperatures to the outdoor climate, so it is not necessary to estimate the clothing values for the space. No humidity or air-speed limits are required when this option is used. As the operative indoor $\left({ }^{\circ} \mathrm{C}\right)$ and the outdoor temperatures $\left({ }^{\circ} \mathrm{C}\right)$ are the only inputs the use of these adaptive model procedures in simulation is straightforward.

Table 1: The most popular and applicable Thermal Comfort models and their respective input variables

\begin{tabular}{|l|l|l|}
\hline Date & Model & Description \\
\hline 1970 & P.O. Fanger & Steady-state model \\
1978 & M. Humphreys & Steady-state model \\
1998 & Brager \& de Dear & Adaptive model \\
2004 & ASHRAE 55 & Adaptive model \\
2005 & ISO 7730,2005 & Steady-state model \\
\hline
\end{tabular}

The evidence-based comparisons of static and Adaptive models for predicting thermal comfort clearly indicate each model has its own pros and cons. For instance, the 
static model is applied globally for different types of buildings. However, the model was developed in laboratory studies, and the effects of building type were not considered. Therefore, the static model is not applicable to free running buildings. The reason may be the static method applied globally requires very limited variables that can be easily obtained and computed quickly.

The Adaptive Model is based on three pillars: behavioural adjustment, physiological adaptation and psychological adaptation. Thus, an adaptation is more than a simple collection of observable properties in a particular individual or space. This means that the set of thermal observable characteristics in PMV should be carefully extended and specified in terms of occupancy and the thermal properties of the building to include actions in human behaviour and the properties of the building fabric.

The purpose of this short review is to identify and arrange the essential TC parameters of building designs based on the most common TC models which are mainly intended for buildings, Table 1. Table 2 then specifies and arranges the essential exchange requirements parameters required for this work.

\section{BIM for Sustainable Design}

A BIM is a digital representation and repository of building data and information. BIM simplifies the automated exchange of digital information between diverse stakeholders and significantly reduces paper-based document delivery. BIM technology enables a number of automated or semiautomated facility-related services such as cost estimates, scheduling and energy simulation analysis (Cheng \& Das 2014). In addition, BIM becomes a universal user interface for architectural design and building performance simulations (Yan et al. 2013).

With BIM, assessing building sustainability becomes a key element of the design process for early-stage environmental analyses. It allows users to explore different aspects, for instance building energy use, orientation, comfort and daylight (Bethany 2017). This can be done by way of linking the BIM model to building simulation tools, which allows calculation of energy use during the early design stages (Dhillon et al. 2014).

BIM and sustainable building design not only can control energy consumption and reduce environmental effects but also can decrease costs and create a comfortable condition and pleasant living environment (Zhang et al. 2015). Brager et al. (2015) suggested that "If building designers and operators can find efficient ways to allow building temperatures to float over a wider range while affording occupants comfort, the potential for energy savings is enormous".

\section{BIM data files and formats}

Data stored in one domain area are often relevant to other domains. Due to the critical lack of information interoperability, it is quite difficult to get a complete crossdomain view of a building in terms of the interaction of data streams in a clear and structured manner. Therefore, significant progress has been made in the area of common data exchange in the building industry with the development of information technology. Today, the Industry Foundation Class (IFC) and Green Building XML (gbXML) are two wide-spread data exchange formats in the AECOO industry and are used between design applications such as BIM and BEPS programs (Kamel \& Memari 2018).

Despite both gbXML and IFC formats being used by the AECOO industry, their adoption does not guarantee highfidelity and meaningful data exchange (Arayici et al. 2018). For instance;

- The gbXML format is not mature enough and has been limited to being used in simple design solutions because of its difficulty to read complex geometries (Bahar et al. 2013). This is one of the major drawbacks in the context of generating reliable models.

- The IFC schema does not capture the ways how information is created and shared by practitioners ( $\mathrm{El} \mathrm{Asmi}$ et al. 2015), (Juan \& Zheng 2014). In other words, without a clear procedure and shared understanding between the actors about what information should be encapsulated in the IFC schema the exchange cannot be automatically and correctly transferred by the IFC schema. For this reason, some specific information can be lost during the exchange process.

The development of specifications for BIM data formats does not guarantee a viable solution to the interoperability issue unless there is a clear specification and guidance for information sharing and the integrated use of BIM for performance-based design (Hijazi et al. 2015). To support the use of IFC, BuildingSMART presented framework for Information Delivery Manual (IDM) sometimes referred to as 29481-1 ISO (2010) methodology that captures and integrates the business process while providing detailed user-defined specifications of information that needs to be exchanged at particular points within a project. To address the need and bridge the gaps, the IFC data file is used, as the ultimate aim of this paper to formulate the exchange requirements that will underpin a MVD for BTCS assessment.

\section{Review for the existing related MVDs}

The goal of MVDs are to enable data exchange through the IFC standard including geometry and non-geometry 
Table 2: End-user input data requirements needed to support BIM based BTCS. These features underpin the IFC exchange model based on the selected Thermal Comfort models that are described in Table 1. The black squares (ם) represent the input data that automatically derived at runtime and black lozenges $(\diamond)$ defined the input data from BIM

\begin{tabular}{|c|c|c|c|c|c|c|c|}
\hline \multirow[b]{2}{*}{$\begin{array}{l}\text { Mathe- } \\
\text { matical } \\
\text { vari- } \\
\text { able }\end{array}$} & \multirow[b]{2}{*}{ Parameter } & \multirow[b]{2}{*}{ Unit } & \multicolumn{5}{|c|}{ Thermal Comfort models } \\
\hline & & & $\begin{array}{l}\text { P.O. } \\
\text { Fanger }\end{array}$ & $\begin{array}{l}\text { M. } \\
\text { Hump- } \\
\text { hreys }\end{array}$ & $\begin{array}{l}\text { Brager } \\
\& \text { de } \\
\text { Dear }\end{array}$ & $\begin{array}{l}\text { ASH- } \\
\text { RAE } \\
55\end{array}$ & $\begin{array}{l}\text { ISO } \\
7730, \\
2005\end{array}$ \\
\hline $\mathrm{Ta}$ & Air temperature & ${ }^{\circ} \mathrm{C}$ & [ & $\mathbf{\square}$ & & $\mathbf{\square}$ & $\mathbf{\square}$ \\
\hline $\mathrm{V}$ & Air velocity & $\mathrm{m} / \mathrm{s}$ & $\mathbf{\square}$ & & & $\mathbf{\square}$ & $\mathbf{\square}$ \\
\hline Clo & Clothing insulation & Clo & $\nabla$ & $\nabla$ & & & $\nabla$ \\
\hline $\mathrm{RH}$ & Relative humidity & $\%$ & $\mathbf{\square}$ & & & $\square$ & $\mathbf{\square}$ \\
\hline $\operatorname{Tr}$ & Mean radiant temperature & ${ }^{\circ} \mathrm{C}$ & $\mathbf{\square}$ & & & $\mathbf{\square}$ & $\mathbf{\square}$ \\
\hline $\mathrm{M}$ & Metabolic rate & met & $\nabla$ & & & & 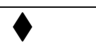 \\
\hline $\mathrm{Ra}$ & Outdoor airflow rate required per unit area & $1 / \mathrm{s} / \mathrm{m}^{2}$ & & & & & $\diamond$ \\
\hline $\mathrm{Ra}$ & Outdoor airflow rate required per unit person & 1/s/person & & & & & 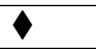 \\
\hline $\mathrm{Pz}$ & Zone population & number & & & & & $\boldsymbol{\nabla}$ \\
\hline$\overline{\mathrm{Az}}$ & Zone floor area & $\mathrm{m}^{2}$ & & & & & 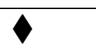 \\
\hline PA & Partial water vapour pressure & $\mathrm{Pa}$ & & & & & $\square$ \\
\hline Trm & Mean Outdoor air temperature & ${ }^{\circ} \mathrm{C}$ & & & $\square$ & [ & \\
\hline Top & Operative temperature & ${ }^{\circ} \mathrm{C}$ & & $\mathbf{\square}$ & $\square$ & $\mathbf{\square}$ & \\
\hline $\mathrm{Ra}$ & Radiant asymmetry & ${ }^{\circ} \mathrm{C}$ & & & & $\mathbf{\square}$ & \\
\hline $\mathrm{Tf}$ & Floor temperature & ${ }^{\circ} \mathrm{C}$ & & $\nabla$ & & $\nabla$ & \\
\hline Trm & Mean monthly outdoor temperature & ${ }^{\circ} \mathrm{C}$ & & & & $\square$ & \\
\hline
\end{tabular}

data, by creating a view of the data which is specific to the needs of those who will use the information. Defining the specification of these requirements manually is complex and burdensome. To simplify this task, there is a set of MVDs specified as legal subsets of the IFC schema that fulfill defined workflow purposes. For instance, in an MVD addressed to meet the needs of BTCS analysis, the internal spaces parameters are exported from the BIM, while in an MVD addressed to meet visualisation needs, e.g. clash detection, the full geometry is parameterised.

In IFC4 the coordination view has been replaced by two official MVDs releases aligning with the two core use cases of model exchange;

The IFC4 Reference view; is to define a standardised subset of the IFC4 schema, a MVD, that is particularly suitable for some BIM work flows that are based on reference models where the exchange is mainly one-directional. The overall goal of the IFC Reference View is to provide workflows where building information models are to be consumed by the widest array of software applications that do not require modifying geometry. Such applications enable viewing, estimating, building analysis, and other downstream analysis.

The IFC4 Design Transfer View (DTV); targets all work flows based on models that are handed over to perform in next work flows, allowing modifications of its content.

Table 3 shows comparison between these MVDs. This work adapts the IFC4 Reference view and extends its capability to support BTCS analysis.

\section{IFC MVD creation methodology}

The first part of this paper involved the definition of a set of exchange information required to support BTCS at the early stage of the building designs. The next sections define and categorise this information using ISO167391:2018, or the IFC data schema representations. The result of the mapping process will be used as a basis for developing an MVD for BIM-based BTCS. In order to classify the target information and create a subset of the IFC4 Reference View, the following steps are taken;

1. specify the related IFC entities based on the categories and subcategories of elements that are required for model exchange. In addition, defining sub-elements that are necessary for establishing the relationships between building elements, for example, IfcProject , IfcRoot and IfcSpace etc;

2. identify the attributes associated with each entity 
Table 3: Table comparing the use of IFC as a Reference View or as a Design Transfer View provided by BuildingSMART

\begin{tabular}{|l|l|}
\hline IFC4 Reference View (RV) & IFC4 Design Transfer View (DTV) \\
\hline \multicolumn{2}{|c|}{ Goals } \\
\hline $\begin{array}{l}\text { - support the referencing workflow, e.g. the result of } \\
\text { the import model is read-only (not allowing modifica- } \\
\text { tions) }\end{array}$ & $\begin{array}{l}\text { - support the handover workflow, e.g allowing import } \\
\text { model for further modifications. }\end{array}$ \\
\hline \multicolumn{2}{|c|}{ Scenario includes } \\
\hline $\begin{array}{l}\text { - take-off and cost estimate } \\
\text { - clash detection } \\
\text { - any analysis-based work flow }\end{array}$ & $\begin{array}{l}\text { - transfer architecture model to engineers } \\
\text { - import model into MEP } \\
\text { - takeover contractors }\end{array}$ \\
\hline $\begin{array}{l}\text { - the exporter's remain the owner } \\
\text { - fast export and import } \\
\text { - surly validity, no further rework expected }\end{array}$ & $\begin{array}{l}\text { - the owner handed over to receiver } \\
\text { - tolerable longer time export and import } \\
\text { - allows for further rework }\end{array}$ \\
\hline
\end{tabular}

IfcProperty, for instance, property names and property values; and

3. define the related objects and the relationship. In an IFC schema, building objects IfcObject and their properties IfcProperty are linked directly by IfcRelDefinesByProperties. The IFC4 Reference View IfcRelDefinesByProperties defines the relationships between property set definitions and objects. For instance, a specific property of IfcPropertySet can be related to a specific object of IfcSpace through IfcRelDefinesByProperties, Figure 2. This provides the assignment of an object type and is described by associating single or multiple properties.

Before going into detail on the process of mapping representation exchange requirements, it is important to explain the fundamental concepts and functional parts of the IFC components that set the scene for MVD development.

- Entities are the main nodes of the schema that include; physical elements like IfcWall for geometry representation and IfcActor for occupants;

- An attribute is basic meta-data about the entity and it where all other information about the entity can be attached;

- The property set is a container class that holds properties within a property tree;

- Properties for element-based entities use an attribute called HasPropertySets. This allows a property set (a group of properties) to be assigned to the entity. Within this property set are the individual properties which describe the entity further or describes its performance. The schema already contains a number of defined property sets and properties. An example for the entity IfcSapce is the property set
Pset_SpaceThermalRequirements with the property SpaceTemperature; and

- A property template defines meta-data for a property including name, description and data type. Data types may be simple such as text or floating-point numbers for particular measures.

\section{IFC MVD mapping process}

A number of information items have been identified that can be obtained from an IFC based BIM before transformation to BTCS input data. The sources of this information are:

- Project/Building information;

- Building geometry and Boundary conditions;

- HVAC System information;and

- Space related data.

Project or building entities typically include very generic information that have to be included within the IFC model before it is exported to the BTCS e.g building location, orientation and unit.

BIM geometry mainly consists of three types of information: building geometry, coordinate systems, and geometry-related semantic information. Building geometry is composed of basic building elements (walls, floors, columns, beams, windows, doors and roofs, etc.), which are usually defined as a collection of planar surfaces that enclose thermal spaces.

The geometry related semantic information refers to the geometric/topological features of each surface. They primarily include the building element that the surface represents and the space that the surface belongs to, the relationships between the surface and other surfaces and 


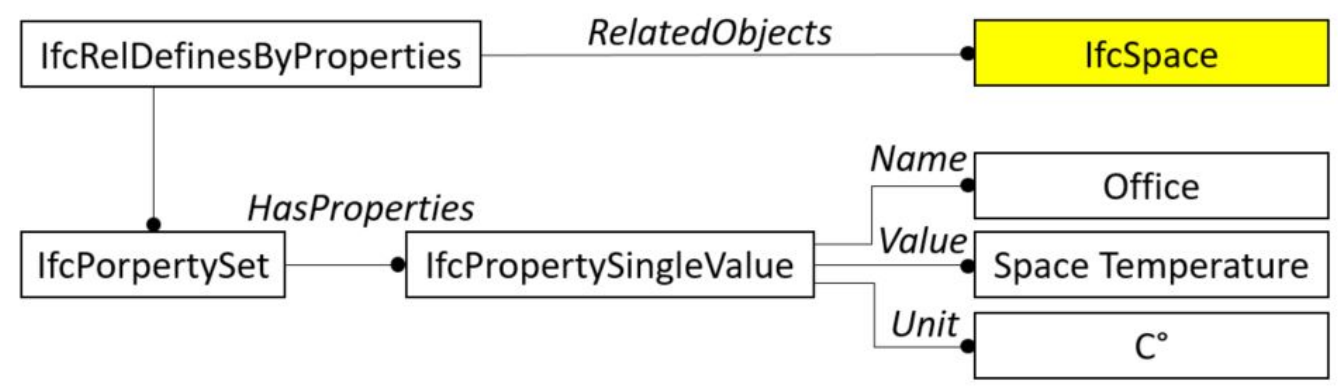

Figure 2: The relation between IfcObject and their properties IfcProperty.

importantly, the condition (i.e. internal space, outdoor or element) of the other side of the building element providing the surface.

Within a BIM, the spaces are volumes that provide for certain functions within a building. A zone is a collection or group of spaces. IFC Zones are different from IFC Spaces insomuch that an IfcZone cannot exist without an IfcSpace. However, an IfcSpace does not need to be associated with a zone. In BTCS tools, e.g EnergyPlus, the zone instances contain the parameters to simulate each thermal zone of the building. Without thermal zones and surfaces, the building cant be simulated. In EnergyPlus, thermal comfort modeling is controlled primarily by the People input object. Input choices include options for selection of the type of thermal comfort model that is desired by the user as well as parameters that serve as inputs to all of the thermal comfort models. While in BIM, most of the parameters that influence thermal comfort levels inside a building can be obtained via IfcSpace.

Over the course of defining and extracting related data for spaces, all of the information defined in table 2 are assigned to the If Space. The space thermal design defines most of thermal property set for all types of spaces to capture building service design values. However, the existing property sets in IfcSpace do not fully support the correct representation needed for BTCS analysis. Therefore, this research defines two additional property sets to overcome the lack of information: Pest_ExtendSpaceOccupancyRequirements and Pest_ExtendSpaceThermalRequirements, as demonstrated in Figure 3. Under these property sets, six additional properties are defined and added to provide relevant data. The properties e.g. Clothing insulation level (Clo) and Outdoor airflow rate required per unit area $(1 / \mathrm{s})$. The definition of property sets describe how sets of properties (usually defined by a name, value, unit triple) are associated to objects or object types, Figure 3 . Table 4 provides a detailed description of appropriate representation of ERs mapped to the corresponding IFC4 scheme.

The model shown in Figure 4 is an excerpted version from

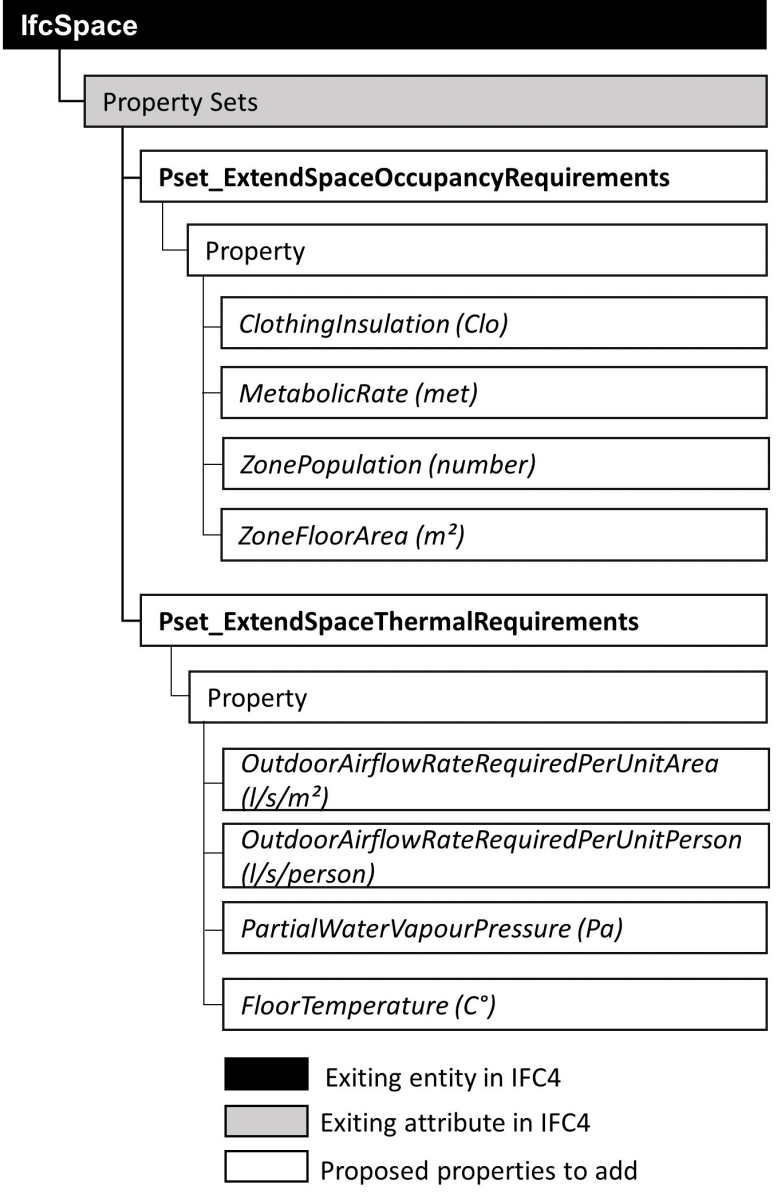

Figure 3: Proposed properties to add in the IFC4 Reference View to support the aimed MVD 
Table 4: Mapping a set defined parameters to the corresponding IFC parameters, name and data types used for IFC MVD export during the BTCS analysis

\begin{tabular}{|l|l|l|l|l|l|}
\hline \multicolumn{3}{|c|}{ Input exchange requirements } & \multicolumn{3}{c|}{ Corresponding IFC parameters } \\
\hline $\begin{array}{l}\text { Mathe- } \\
\text { matical } \\
\text { variable }\end{array}$ & Parameter & Unit & Entity & Property set & Data Type \\
\hline $\mathrm{Clo}$ & Clothing insulation & $\mathrm{Clo}$ & IfcSpace & Pest ExtendSpaceOccupancyRequirements & IfcReal \\
\hline $\mathrm{M}$ & Metabolic rate & $\mathrm{Met}$ & IfcSpace & Pest_ExtendSpaceOccupancyRequirements & IfcReal \\
\hline $\mathrm{Ra}$ & Outdoor airflow rate required per unit area & $1 / \mathrm{s} / \mathrm{m}^{2}$ & IfcSpace & Pest_ExtendSpaceThermalRequirements & IfcCountMeasure \\
\hline $\mathrm{Rp}$ & Outdoor airflow rate required per person & $1 / \mathrm{s} / \mathrm{p}$ & IfcSpace & Pest_ExtendSpaceThermalRequirements & IfcCountMeasure \\
\hline $\mathrm{Pz}$ & Zone population & number & IfcSpace & Pest_ExtendSpaceOccupancyRequirements & IfcReal \\
\hline $\mathrm{Az}$ & Zone floor area & $\mathrm{m}^{2}$ & IfcSpace & Pest_ExtendSpaceOccupancyRequirements & IfcReal \\
\hline $\mathrm{PA}$ & Partial water vapour pressure & $\mathrm{Pa}$ & IfcSpace & Pest_ExtendSpaceThermalRequirements & IfcCountMeasure \\
\hline tf & Floor temperature & ${ }^{\circ} \mathrm{C}$ & IfcSpace & Pest_ExtendSpaceThermalRequirements & IfcCountMeasure \\
\hline
\end{tabular}

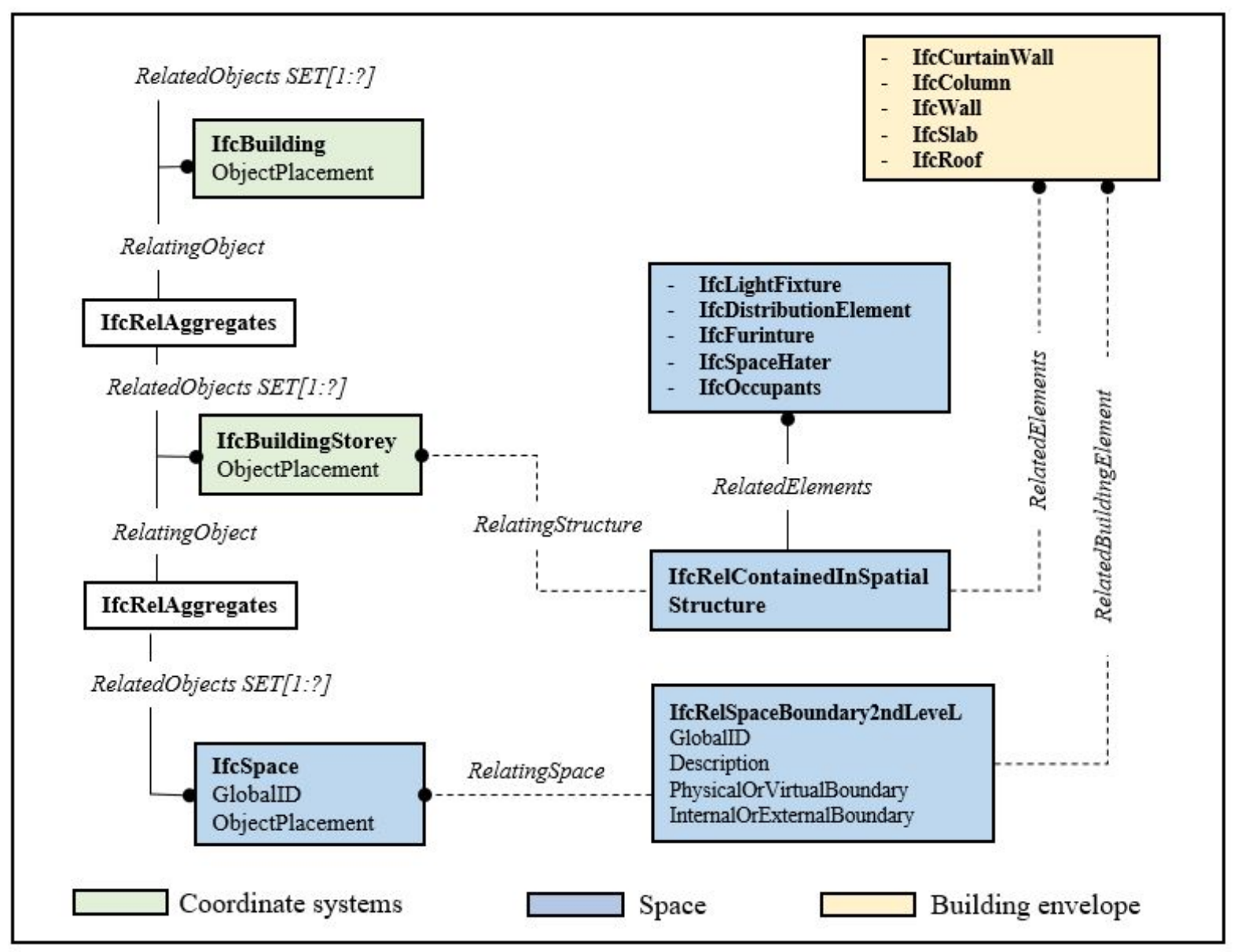

Figure 4: The IFC data structure to store semantic for Thermal Comfort data represents IfcSpace objects and their relations defined in an IFC's schema e.g IfcRelSpaceBoundary $2^{\text {nd }}$ level and IfcBuildingElement. 
the full semantic information of the exchange models with a focus on the IfcSpace entity. There are main core elements and containers of elements that store information about building elements in general; therefore, IfcSpace is connected to a building coordination system and building envelope.

\section{Discussion}

The current potential of BIM for indoor environmental performance assessment is high and is based on literature analysis conducted in this study. BIM supports BTCS analysis because required information about quantities can be exported from the BIM authoring software with the help of. These can be further linked with building geometry and structural elements and building materials. According to Jung et al. (2018) the amount of environmental performance information retrieved from the model with the help of IFC is significant, both in terms of quantities and quality but it may involve further manual handling.

The indoor environmental impact should be assessed based on as-built information, and similarly specific data for the internal spaces (Kim \& Yu 2016). At present, the challenge is to find a reliable and interoperable solution by combining BIM-based with BTCS tools for determining comfort levels. This absence causes thermal comfort to be assessed separately from the architects mode.

Regarding development towards performance-based design, the main challenge remains with data exchange between BIM authoring tools and performance assessment tools. To improve data exchange or more specifically the data set needed for different use cases with multiple BIMbased models, more MVDs should be defined and implemented to provide the end-user with the tools and processes they need. However, the implementation agreements such as IDM/MVDs for IFC do not necessarily allow exchanging all that information. At present, assessment and simulation tools are typically being integrated into the model authoring software either one by one or used separately. Therefore, the need for not only technical standardisation but also process standardisation to better understand who should provide each piece of information.

In this work, the application of the MVD is limited for thermal comfort assessment during buildings design phase. However, TC is very complex due to variables in the indoor environments, and the information needed to fully comply with perceived TC measures are too detailed to be captured by an IFC model on one particular dynamic calculation tool. Research efforts are needed in this direction, as TC should not be over looked to be applied only during the buildings design phase.

Based on the interviews conducted by Jung et al. (2018), Energy performance and Thermal Comfort have gained most of the attention in the tools evaluating the quality of the building design. It remains an open question as to whether if the implementation of MVDs will become common and solve the data exchange challenges.

\section{Conclusions and Future Work}

This paper identified and arranged the essential thermal comfort parameters for building designs and formulated an ERs model for BTCS assessment during design processes of high performance buildings. This work presented a novel ERs model for a BIM-based approach to BTCS assessment. In the first task, we defined a specific data representation of the required information necessary for creating IFC ERs models for BTCS. The results of this module are being used as a first step in developing MVD, a concept binding diagrams reuse the existing IFC4 Reference View corresponding to each building entity.

The implementation of this work is expected to be a unique contribution to address the problem of manual rework and its associated knowledge by enabling the efficient and economic creation of Thermal Comfort prediction-based design. Regarding development towards performance-based design, the proposed BIM-based model and MVD provides the AECOO industry with the tools and processes required to support performance-based design along the design process and in early phases.

For future work, once creation and/or modification of MVD is completed, the validation stage can be performed to ensure that the outputs fulfill the requirements. A IfcDoc tool checker can be used for this validation. It should be noted that software vendors should first implement the proposed MVD in their BIM platforms so that designers do not need to spend extra time to prepare their models for BTCS assessment.

\section{Acknowledgements}

We thank all colleagues, who provided helpful comments on previous versions of this document.

This work was supported by funded by the Department of Education of the Kingdom Saudi Arabia, Grant number IRJN1502.

This publication has emanated in part from research supported by a research grant from Science Foundation Ireland (SFI) under the SFI Strategic Partnership Programme Grant number SFI/15/SPP/E3125. The opinions, findings and conclusions or recommendations expressed in this material are those of the author(s) and do not necessarily reflect the views of the Science Foundation Ireland.

\section{References}

Arayici, Y., Fernando, T., Munoz, V. \& Bassanino, M. (2018), 'Interoperability specification development for 
integrated BIM use in performance based design', $A u$ tomation in Construction 85, 167-181.

ASHARE (2013), 'ASHRAE Standard 55-2010: Thermal Environmental Conditions for Human Occupancy', American Society of Heating, Refrigeration and Air conditioning Engineers ASHRAE Sta, 58.

Bahar, Y., Pere, C., Landrieu, J. \& Nicolle, C. (2013), 'A Thermal Simulation Tool for Building and Its Interoperability through the Building Information Modeling (BIM) Platform', Buildings 3(2), 380-398.

URL: http://www.mdpi.com/2075-5309/3/2/380/

Bethany, P. (2017), 'Top 10 Benefits of Building Information Modeling (BIM)'.

URL: https://www.scan2cad.com/cad/benefits-of-bim/

Bragança, L., Vieira, S. M. \& Andrade, J. B. (2014), 'Early Stage Design Decisions : The Way to Achieve Sustainable Buildings at Lower Costs', The Scientific World Journal 2014.

URL: http://dx.doi.org/10.1155/2014/365364

Brager, G. S., Zhang, H. \& Arens, E. (2015), 'Evolving opportunities for providing thermal comfort', Building Research \& Information 43(3), 274-287.

URL: http://dx.doi.org/10.1080/09613218.2015.993536

Cheng, J. C. \& Das, M. (2014), 'A bim-based web service framework for green building energy simulation and code checking', Journal of Information Technology in Construction 19(January), 150-168.

URL: https://www.engineeringvillage.com/share/document.url? mid $=c p x_{3} 522 e 76 e 1491 b 05-$ aca0M6a5c101781631 - 25database $=c p x$

de Dear, R. J. \& Brager, G. S. (1998), Developing an adaptive model of thermal comfort and preference, Technical Report Pt 1A, Macquarie University, Sydney. URL: http://www.cbe.berkeley.edu/research/otherpapers/de Dear - Brager 1998 Developing an adaptive model of thermal comfort and preference.pdf

Dhillon, R. K., Jethwa, M. \& Rai, H. S. (2014), 'Extracting Building Data from BIM with IFC', Engineering and Technology 11(1), 3.

URL: $\quad$ http://searchdl.org/public/journals/2014/IJRTET/11/1/1500.pdf

El Asmi, E., Robert, S., Haas, B. \& Zreik, K. (2015), 'A standardized approach to BIM and energy simulation connection', International Journal of Design Sciences and Technology 21(1), 59-82.

EN-ISO-7730 (2005), Moderate Thermal EnvironmentsDetermination of the PMV and PPD Indices and Specification of the Conditions of Thermal Comfort., Technical report, ISO - International Organization for Standardization.

URL: https://www.iso.org/standard/39155.html

European Parliament (2010), European Parliament and Council, 2010a. Directive 2010/31/EU of the European Parliament and of the Council on the energy performance of buildings, Technical Report ISSN 1725-2555, European Council.

Hijazi, M., Kensek, K. \& Konis, K. (2015), Bridging the gap : supporting data transparency from BIM to BEM, in 'Future of Architectural Research Centers Consortium', Los Angeles,CA, pp. 149-.

URL: $\quad$ https://www.brikbase.org/sites/default/files/ARCC2015_50_hijazi.pdf

Holmström, J., Singh, V. \& Främling, K. (2015), 'BIM as Infrastructure in a Finnish HVAC Actor Network: Enabling Adoption, Reuse, and Recombination over a Building Life Cycle and between Projects', Journal of Management in Engineering 31(1), A4014006.

URL: $\quad$ http://ascelibrary.org/doi/10.1061/\%28ASCE\%29ME.1943-5479.0000305

ISO (2010), 'BS ISO 29481-1 : 2010 - Building information modelling - Information delivery manual - Part 1: Methodology and format', ISO p. 34

URL: $\quad$ http://www.iso.org/iso/cataloguedetail.htm? csnumber $=45501$

Juan, D. \& Zheng, Q. (2014), 'Cloud and Open BIM-Based Building Information Interoperability Research', Journal of Service Science and Management (April), 47-56. URL: http://file.scirp.org/Html/1-9201641_44958.htm

Jung, N., Häkkinen, T. \& Rekola, M. (2018), 'Extending capabilities of bim to support performance based design'.

Kamel, E. \& Memari, A. M. (2018), 'Automated Building Energy Modeling and Assessment Tool (ABEMAT)', Energy 147, 15-24.

Kassem, M., Iqbal, N., Kelly, G., Lockley, S. \& Dawood, N. (2014), 'Building Information Modelling : Collaborative Design Processes Protocols', Journal of Information Techology in Construction 19(July), 126-149.

Kim, J. B., Jeong, W., Clayton, M. J., Haberl, J. S. \& Yan, W. (2015), 'Developing a physical BIM library for building thermal energy simulation', Automation in Construction 50(C), 16-28.

URL: http://dx.doi.org/10.1016/j.autcon.2014.10.011

Kim, K. \& Yu, J. (2016), 'A process to divide curved walls in IFC-BIM into segmented straight walls for 
building energy analysis', Journal of Civil Engineering and Management 22(3), 333-345.

URL: $\quad$ http://www.tandfonline.com/doi/full/10.3846/13923730.2014.897975

Sanhudo, L., Ramos, N. M., Poças Martins, J., Almeida, R. M., Barreira, E., Simões, M. L. \& Cardoso, V. (2018), 'Building information modeling for energy retrofitting A review'.

Soares, N., Bastos, J., Pereira, L. D., Soares, A., Amaral, A. R., Asadi, E., Rodrigues, E., Lamas, F. B., Monteiro, H., Lopes, M. A. \& Gaspar, A. R. (2017), 'A review on current advances in the energy and environmental performance of buildings towards a more sustainable built environment', Renewable and Sustainable Energy Reviews 77, 845-860.

URL: $\quad$ https://www.sciencedirect.com/science/article/pii/S1364032117305270

Szelag, R. (2017), The Use of BIM Technology in the Process of Analyzing the Increased Effort of Structural Elements, in 'Procedia Engineering', Vol. 172, pp. 10731076 .

Tuohy, P. G. \& Murphy, G. B. (2015), 'Closing the gap in building performance: Learning from BIM benchmark industries', Architectural Science Review 58(1), 47-56.

Yan, W., Clayton, M., Haberl, J., Jeong, W., Kim, J. B., Texas, A. \& Station, C. (2013), INTERFACING BIM WITH BUILDING THERMAL AND DAYLIGHTING MODELING, in '13th Conference of International Building Preformance Simulation Association', number Yan2013, Chambéry, France, pp. 9-11.

Yau, Y. H. \& Chew, B. T. (2014), 'A review on predicted mean vote and adaptive thermal comfort models'.

Zhang, J., Seet, B.-C. \& Lie, T. (2015), 'Building Information Modelling for Smart Built Environments', Buildings 5(1), 100-115.

URL: http://www.mdpi.com/2075-5309/5/1/100/ 